\title{
MOVIMENTO ESTUDANTIL NO BRASIL: LUTAS PASSADAS, DESAFIOS PRESENTES
}

\author{
Silene de Moraes Freire ${ }^{1}$ \\ Universidad do Estado do Rio do Janeiro - Brasil \\ Grupo de Investigación HISULA. SHELA \\ silene-freire@ig.com.br
}

Recepción: 30/05/2008

Evaluación 01/06-15/09/2008

Aceptación: 29/09/2008

Artículo de Reflexión

\section{RESUMEN}

El presente artículo, se propone contribuir para el todavía incipiente debate, en América Latina, en torno de la trayectoria del movimiento estudiantil brasileño, sus avances y retrocesos en lo referente a los diversos contextos históricos de sus luchas. De este modo, la intención es contribuir para la comprensión de la historia del movimiento estudiantil en Brasil con base en la comprensión del significado de las luchas pasadas, y de los desafíos actuales.

Palabras Claves: Historia, movimiento estudiantil, Brasil.

\footnotetext{
${ }^{1}$ Professora Adjunta da Graduação e Pós-Graduação (mestrado e doutorado) da Faculdade de Serviço Social da Universidade do Estado do Rio de Janeiro (UERJ). Doutora em Sociologia pela Universidade de São Paulo, Procientista da UERJ, Pesquisadora do CNPq, Coordenadora do Programa de Estudos de América Latina e Caribe-PROEALC- do Centro de Ciências Sociais da UERJ.
} 


\title{
STUDENT MOVEMENT IN BRAZIL : PAST FIGHTS, NOWADAYS CHALLENGES
}

\author{
Silene de Moraes Freire \\ Universidad do Estado do Rio do Janeiro - Brasil \\ Grupo de Investigación HISULA. RHELA \\ silene-freire@ig.com.br
}

\begin{abstract}
The present article intends to make a contribution to the fragile debate on student movements in Latin America. The trajectory of the Brazilian student movement, its advances and backward movements are inserted in diverse historical contexts of its fights. Understanding the student movement history in Brazil based on the comprehension of the meaning of the passed fights, and the present challenges becomes the main purpose of this essay.
\end{abstract}

Key Words: History, student movement, Brazil

\section{INTRODUÇÃO}

"Ou os estudantes se identificam com o destino do seu povo, com ele sofrendo a mesma luta; ou se dissociam do seu povo, e nesse caso, serão aliados daqueles que exploram o povo". (Florestan Fernandes,1997)

O presente estudo faz parte de nossas pesquisas acerca dos rumos dos movimentos sociais no Brasil, realizadas no Programa de Estudos de América Latina e Caribe da Universidade do Estado do Rio de Janeiro. Para desenvolver o mesmo, utilizamos como metodologia elementos fundamentais para a construção de uma investigação de caráter teórico-interpretativo. Desse modo, a metodologia incluiu as concepções teóricas de abordagem dos fatos selecionados para reflexão. Também buscamos uma aproximação histórica com todos os momentos de protagonismo do movimento estudantil em nosso país. Aspectos de cada conjuntura, nacional e internacional foram levantados em fontes bibliográficas diversas (livros, jornais de diferenets períodos, revistas, teses, dissertações, etc) com o objetivo de inserir historicamente cada luta desse segmento educacional. Assim, a meta da narrativa do estudo apresenta sua consonância com a metodologia desenvolvida, dando sentido ao movimento estudado e ressaltando sua importância em cada contexto diferenciado. Entendemos por metodologia o caminho do 
pensamento e a prática exercida na abordagem da realidade. Neste sentido, a metodologia ocupa um lugar central na teoria e está sempre referida a elas.

Neste estudo pretendemos oferecer um conjunto de análises capazes de contribuir no aprofundamento de nosso objeto de investigação (a trajetória do movimento estudantil no Brasil) contextualizando o significado da experiência desse movimento em nosso país. Diante disso, salienta-se que esta investigação contará com uma metodologia qualitativa, utilizando um embasamento teórico e dados históricos empíricos para melhor fundamentarem os conceitos e reflexões. Não almejamos oferecer através de nossa investigação uma interpretação da "singularidade" histórica do movimento estudantil brasileiro: o objetivo é mostrar como a complexidade e a singularidade de uma experiência pode ser abordada por meio de uma perspectiva genérica, que articulada com determinações particulares, permite um delineamento totalizante, evidenciado nos seus vínculos com políticas mais amplas e suas semelhanças não circunstanciais com experiências desenvolvidas em outras sociedades. Assim sendo, ao considerarmos a particularidade e complexidade de nosso objeto de estudo, estamos enfatizando que o mesmo faz parte de uma totalidade, em movimento, repleta de contradições.

Há exatamente 40 anos passados, ou seja , no ano de 1968, o mundo encontrava-se em plena efervescência - no Vietnã, na Alemanha, nos guetos norte-americanos, no México e em Praga. No mês de março desse mesmo ano na França, estudantes e operários se põem em movimento apresentando inúmeros questionamentos ao poder. De maio a junho, na França, sob o afã inicial da juventude, a indignação cresce cada vez mais e passa a apresentar diferentes formas de resistência política, nos palcos das universidades francesas de Nanterre e Sorbonne, nas fábricas e nas ruas do Quartier Latin em Paris. O mês de maio de 1968 representou o auge de um momento histórico de intensas transformações políticas, culturais e comportamentais que marcaram a segunda metade do século XX. Não por acaso, maio de 68 se tornou uma página de uma história mundial de contestação à guerra, à sociedade de consumo e ao autoritarismo. Um velho mundo ruía e os estudantes franceses protagonizavam, juntamente com os operários do país, um movimento que marcou a história estudantil para sempre. A partir de manifestações estudantis ocorridas nas universidades francesas, irromperam sucessivos movimentos de protestos em diversas universidades de países da Europa e das Américas, que ganharam uma dimensão ainda maior com a ampliação das revoltas para a classe trabalhadora.

Como o historiador Eric Hobsbawm afirma, no livro "A Era dos Extremos" (1995), a Idade Média acabou de repente, em meados da década 
de 1950. Para Hobsbawm, o crescimento repentino dos números da educação, especialmente do ensino superior, são um dos motivos que explica as mudanças da década. Essas mudanças são traduzidas pelos significativos números de estudantes matriculados nas universidades. Segundo o historiador, no fim da Segunda Guerra, havia menos de 100 mil estudantes na França. Em 1960 eram mais de 200 mil e, nos dez anos seguintes, esse número triplicou para 651 mil. Essa massa de estudantes despejadas nas universidades revelava que a mesma não estava preparada, de nenhuma forma, para tal influxo.

Não surpreende que a década de 1960 tenha se tornado a década da agitação estudantil. Mesmo que os anos 60 tenham sido associados às subversões, a 'revolução continuada' e a 'sociedade do espetáculo', esses anos foram, sobretudo, associados às rebeliões estudantis. Não podemos dizer que era uma época de escassez material, e talvez por isso mesmo os estudantes universitários acharam que tudo poderia ser diferente. Para Hobsbawm (1995), eles "podiam pedir mais" da nova sociedade que tinham imaginado.

Uma onda de rebeliões fez parte desse cenário de rebeldia estudantil. Assim, greves operárias por maiores salários e melhores condições de trabalho também surgiram em diferentes territórios.

O mundo assistiu, para além da emblemática experiência francesa, à irrupção de lutas de um novo tipo contra a sociedade de consumo, modo de vida e valores da sociedade do capital, ainda em sua fase neocolonialista.

Na América Latina, os confrontos do período também foram motivados por questões ligadas à educação, e por conta das ditaduras militares, como registrou Guilhon Albuquerque (1977). No México, por exemplo, nas universidades e nas ruas os confrontos deixaram dezenas de mortos. No Uruguai, violentos confrontos levam o governo a decretar estado de sítio. Na Argentina, Colômbia e Venezuela, estudantes ocupam universidades, decretam greves, e se envolvem em intensos confrontos com policiais e forças do Exército.

Se a experiência francesa foi considerada um marco internacional do movimento estudantil, também é correto dizer que não foi a única que revelou o potencial da organização de estudantes. No Brasil, por exemplo, o ano de 1968, também é um marco revelador do potencial do movimento estudantil naquela época.

Tais aspectos revelam o significado do presente estudo que, objetiva resgatar e analisar a trajetória do movimento estudantil brasileiro, evidenciando seus avanços e recuos em consonância com os diferentes contextos históricos de suas lutas. 
Em 2008, 40 anos após os movimentos estudantis terem mostrado ao mundo sua capacidade de questionamento e organização, a trajetória desses movimentos na América Latina ainda é pouco conhecida, não apenas nesse período. Nossa intenção é contribuir para a compreensão da história do movimento estudantil no Brasil com base no entendimento do significado de suas lutas passadas, e dos desafios presentes.

\section{O Auge do Movimento Estudantil Brasileiro: A Luta Contra a Ditadura Militar}

$\mathrm{Na}$ década de 1960, a progressiva expansão do sistema de ensino superior público também ocasionou o aumento das vagas nas universidades e conseqüente crescimento do número de estudantes universitários na sociedade brasileira.

Organizados, os estudantes universitários brasileiros constituíram um importante movimento estudantil que influenciou o cenário da política nacional. As lideranças estudantis eram adeptas das ideologias de esquerda. Por conta disso, depois do golpe militar de 1964 o governo desarticulou e colocou na ilegalidade a mais importante entidade estudantil, a União Nacional dos Estudantes (UNE). ${ }^{2}$

A UNE atuou na coordenação e direção do movimento estudantil em âmbito nacional. Mesmo na ilegalidade, as lideranças estudantis mantiveram a UNE em funcionamento e tentaram reorganizar o movimento estudantil. As maiores oposições do movimento estudantil à ditadura militar ocorreram no Governo Costa e Silva (1967-1969), que se caracterizou pelo avanço do processo de institucionalização da ditadura. Em 24 de maio de 1967, dizendo reconhecer que os conflitos se acirraram e que as coisas ameaçavam ir longe demais, Costa e Silva opta sem hesitação pelo endurecimento. Tal endurecimento marca o início de um processo de radicalização que recrudesceria nos anos seguintes. Esse processo, irá acabar com os parcos espaços democráticos, abertos pela Constituição de 1967, que tiveram uma significativa importância na organização

\footnotetext{
${ }^{2}$ A UNE foi criada em 11 de agosto de 1937. Em 1942, promove manifestação em defesa da entrada do Brasil na Segunda Guerra contra a Alemanha.Em 1947, promove a campanha: o petróleo é nosso ! No campo educacional, a entidade defendia a escola pública. No segundo governo Vargas, estudantes ligados a União Democrática nacional -UDN- assumem a entidade. Em 1961, uma chapa de jovens universitários católicos (JUC) vence a eleição. A UNE participa da campanha da legalidade, em defesa da posse do presidente João Goulart, e passa a reivindicar a reforma universitária. Com o golpe militar de 1964 a UNE é posta na ilegalidade e constrói a trajetória que discutiremos nesse artigo. A respeito ver: MENDES JR., Antônio (1982) Movimento Estudantil no Brasil, São Paulo, Brasiliense.
} 
de setores oposicionistas. ${ }^{3}$ Não por acaso, entre 1967 e 1968 ocorre uma verdadeira onda de movimentos de oposição. Nesse contexto, três áreas vão se destacar pela mobilização e articulação (a estudantil, a operária e a Frente Ampla $)^{4}$ conseguindo abalar as estruturas políticas do país.

O movimento estudantil realizou nesse período, grande mobilização contra o governo. A organização dos estudantes foi impulsionada na resistência às demissões arbitrárias de professores e aos limites impostos à autonomia universitária e sua própria organização, tendo como maior exemplo a extinção da União Nacional dos Estudantes - UNE. Ao mesmo tempo em que os estudantes ampliavam seu movimento e promoviam grandes manifestações, com base em problemas localizados em universidades específicas, também passaram a se organizar contra as injustiças existentes em determinadas instituições de ensino. Foi numa dessas lutas específicas que os estudantes realizaram uma campanha pela melhoria da alimentação fornecida aos estudantes pobres - no restaurante do Calabouço, no Rio de Janeiro. No bojo da campanha um pequeno grupo organizou uma dramatização das queixas em frente ao restaurante. No dia 28 de março de 1968, durante uma apresentação do grupo, um batalhão da polícia militar da Guanabara foi ao local e disparou contra os estudantes, matando instantaneamente o estudante Edson Luís Souto. No dia seguinte vários jornais noticiavam na primeira página: "Polícia mata estudante em choque no calabouço". ${ }^{5}$

\footnotetext{
${ }^{3}$ Foi no governo de Costa e Silva que o país conheceu o mais cruel de seus Atos Institucionais. Em 13 de dezembro de 1968, o ministro da Justiça, Gama e Silva, apresentou ao Conselho de Segurança Nacional o AI 5, que entregou o país às forças mais retrógradas e violentas de nossa história recente. O Ato abrangia inúmeras medidas, algumas das quais merecem destaque: pena de morte para crimes políticos, prisão perpétua, fim das imunidades parlamentares, transferência de inúmeros poderes do Legislativo para o Executivo, etc.

${ }^{4}$ A Frente Ampla definia-se como um movimento de oposição, e era composta basicamente de trabalhistas (do ex-PartidoTrabalhista Brasileiro) e de setores das classes médias urbanas. Buscava, atuar em todas as linhas, procurando o diálogo com as lideranças sindicais e estudantis, e manter a opinião pública mobilizada. À medida que os líderes da Frente Ampla foram ajustando seus pontos de vista face à situação nacional, o movimento foi definindo melhor seus objetivos e se ampliando. Assim, no mês de setembro de 1967, os principais líderes da Frente reuniram-se com o expresidente João Goulart, exilado em Montevidéu, Uruguai, para discutir as atividades da oposição e definir metas comuns. Segundo Alves, "embora ainda não estivesse suficientemente organizada para canalizar todas as formas de dissensão, a frente foi recebida entusiasticamente por amplos setores políticos e da opinião pública". (ALVES, 1884:130). Como não poderia deixar de ser, o Pacto gerou fortes reações nos meios militares, especialmente junto à "linha dura". Em março de 1968, as primeiras conseqüências do avanço da Frente já podiam ser notadas. Como resposta às pressões internas, no dia 5 de abril o Ministro da Justiça Gama e Silva, após reunirse com os Ministros militares e ciente do apoio de Costa e Silva junto às lideranças militares, baixou decreto-lei proibindo a Frente Ampla.

${ }^{5}$ JORNAL do Brasil. (1968). Polícia mata estudante em choque no calabouço, de 29 de março. Brasil. p. 22.
} 
A morte do estudante emocionou o país e abriu caminho para a radicalização política. O episódio funcionou como um elemento aglutinador da indignação popular reprimida e resultou em demonstrações de massa, no Rio de Janeiro, que alcançaram proporções típicas de uma rebelião social. $\mathrm{O}$ regime não cedeu diante do clima de tensão e protestos na cidade, pelo contrário, na missa fúnebre para o estudante, realizada na Igreja da Candelária, cerca de 30.000 pessoas compareceram e ao deixarem a Igreja foram atacadas pela polícia. A multidão se viu ameaçada de massacre pela polícia, e a tragédia só foi evitada pela postura enérgica dos padres da igreja católica que exigiram que a polícia deixasse a população ir em paz. A Igreja protestou publicamente contra a invasão do templo durante a realização de um ato religioso. A partir desse momento, segundo Alves, a firme posição adotada pela hierarquia religiosa propiciou " uma aliança informal: os estudantes eram agora abertamente apoiados pela Igreja, a imprensa e, de modo geral, as classes médias do Rio de Janeiro, que poucos anos antes haviam apoiado o golpe militar por medo de uma ditadura comunista". ${ }^{6}$

No dia 25 de junho de 1968, uma grande passeata, que ficou conhecida como a "Passeata do Cem Mil", realizou-se no centro do Rio de Janeiro, em frente à catedral. Nesse momento, ficava claro que outros setores da população também se juntaram aos protestos anti-governamentais iniciados pelos estudantes, como observou Almeida Jr. ${ }^{7}$.

O clima de contestação refletia-se, naturalmente, no movimento da classe trabalhadora. Que por sua vez reproduziu-se no plano nacional com a criação do Movimento Intersindical Antiarrocho (MIA). Assim, várias comissões das fábricas de Osasco, São Paulo, passaram a investir em atividades que se destinavam a elevar o grau de politização dos trabalhadores. $\mathrm{O}$ trabalho de mobilização das bases contou com a ajuda do movimento estudantil, segundo Fávero. ${ }^{8}$

Um movimento organizado nos moldes de Osasco, não podia ser tolerado pelo regime. Desse modo no segundo dia de greve o sindicato foi literalmente esmagado e muitos membros de sua liderança engrossaram a lista de desaparecidos.

É preciso frisar para seqüência de nosso estudo que mesmo derrotada a atuação dos movimentos oposicionistas chegou ao auge no ano de 1968. A Frente Ampla promovia comícios, passeatas e reuniões e havia ampliado suas

\footnotetext{
${ }^{6}$ ALVES MOREIRA, María Helena. (1984): Estado e Oposição no Brasil (1964-1984), Petrópolis, VOZES. p. 354.

${ }^{7}$ ALMEIDA JR., Antônio Mendes de. (1981): Movimento Estudantil no Brasil.São Paulo, Brasiliense, (coleção Tudo É História, No 23) p.125.

${ }^{8}$ FAVERO, María de Lourdes de Albuquerque. (1995): UNE em Tempo de Autoritarismo.Rio de Janeiro, Ed. UFRJ. p. 170.
} 
bases de apoio conseguindo adesão até mesmo de alguns setores das Forças Armadas. Por outro lado, o movimento estudantil começou a se reorganizar também nesse período. Além da exigência de retorno a democracia, os estudantes passaram a se opor à política educacional do governo, que havia realizado um acordo de cooperação com o governo norte-americano, conhecido como o acordo MEC-USAID (siglas que representam o Ministério da Educação e Cultura brasileiro em associação com o Programa NorteAmericano de Assistência aos países pobres).Os estudantes promoveram inúmeros atos e protestos públicos contra o que chamavam de interferência dos Estados Unidos no sistema educacional brasileiro.

\section{Os Novos Atores da Cena Política No Contexto da Redemocratização do Brasil}

No Brasil a nova fisionomia dos movimentos sociais foi se constituindo apoiada pelo ciclo expansivo da economia, a partir da segunda metade dos anos 60 e no transcurso dos anos 70 para ganhar seus contornos definidos já no processo de crise da ditadura militar. No desenvolvimento da resistência democrática, esses movimentos foram ganhando características comuns e diferenciadas, conforme sua prática social e política. Saudados por alguns analistas nos anos 70 como a nova face da sociedade civil, como novos sujeitos sociais; criticados por outros, nos anos 80, como meros grupos de pressão articulados por lobbies com interesses político-partidários e/ou religiosos; o fato real é que os movimentos sociais inscreveram em leis e projetos institucionais suas demandas e lutaram por espaços democráticos junto aos órgãos públicos. O grande saldo desse processo foi o caráter educativo, de aprendizagem, que seus participantes tiveram.

Foi neste contexto de reconhecimento dos 'novos atores na cena política ' que algumas organizações vão traçar o perfil da sociedade civil portadora de um projeto democrático que se desejava construir em contraposição a ditadura militar. Assim, construíram a sua trincheira, sob formas mais ou menos espontâneas, de defesa e resistência, ao redor de suas reivindicações mais imediatas e elementares, como se refere aos problemas de saúde, transporte, moradia, etc. Os movimentos desse tipo ficam conhecidos como movimentos sociais populares urbanos e marcam a década de 70 e 80 no Brasil, tendo sido considerado, por alguns analistas como fonte de renovação nas ciências sociais e na forma de fazer política. Os movimentos de base cristãos, sob inspiração da Teologia da Libertação fazem parte deste momento histórico. Não por acaso, é nesse cenário que surgem as Comunidades Eclesiais de Base (CEBs). ${ }^{9}$

\footnotetext{
${ }^{9}$ A respeito das CEBs ver: TEIXEIRA, Faustino Luiz C. (1988): A gênese das CEBs no Brasil. 1. ed. São Paulo: Paulinas, v. 1. e TEIXEIRA, Faustino Luiz C. (1993): CEBs: cidadania e modernidade. 1. ed. São Paulo: Paulinas, 1993. 243 p.
} 
Ainda na ditadura militar dos anos 70 e início dos 80 , falava-se muito no impacto da atuação das CEBs no campo sócio-político, enquanto geradoras de uma nova consciência das camadas populares e fator de grande importância no processo de libertação dos pobres. Essas pequenas comunidades cristãs, de 20 a 100 membros, eram consideradas um novo sujeito popular, capaz de reverter a situação de pobreza e apontando para uma nova sociedade mais justa e fraterna.

Faz-se mister ressaltar que se no contexto dos anos 70 e 80 do século passado as CEBs possuem um protagonismo de representação da sociedade civil capaz de lutar pela democratização do Estado brasileiro, na ultima década do século passado há uma inversão dessa crença. Nos anos 90, as CEBs entram numa vida submersa, bem diferente do momento político da ditadura quando tudo era submerso e as CEBs emergiam com muita força. Alguns analistas caracterizam as CEBs dos anos 90 como voltadas para si mesmas, tendo perdido muito do espírito de mudança. Tal compreensão da trajetória desse movimento não pode deixar de perceber que as CEBs seguiram o caminho de grande parte dos movimentos sociais, que em geral, entram em crise: de identidade, de rumos, de objetivos, definições, projetos, mobilizações etc. As causas são várias, destacando-se as de ordem interna, dadas pelas relações entre as bases, as lideranças e as assessorias num contexto neoliberal onde a fragmentação das experiências passa a guiar as relações sociais.

No que concerne aos movimentos operários, a história não é muito diferente, as greves que têm início no final dos anos 70 na indústria paulista caracterizam uma nova etapa de luta da classe operária, no país. Segundo Oliveira ${ }^{10}$ podemos situar o movimento operário, em todo período, como tendo percorrido três fases fundamentais. A da organização e resistência nas fábricas, período em que as lutas se expressavam de forma isolada, por empresas: a fase de ofensiva e organização ampla, a partir de 1979, quando então eclodiram as grandes greves, por categorias, acelerando-se o processo de organização sindical e intersindical culminando na I CONCLAT, até a divisão orgânica, em 1983 e a fase que vai até o final dessa década, de ampliação e consolidação do movimento através da organização em sindicatos. A partir do final da década de 70 aprofunda-se a organização dos sindicatos e das articulações intersindicais simultâneo ao crescimento do movimento grevista que se caracteriza pela mobilização de grandes massas de trabalhadores e sua ampliação a várias categorias, expressando já num maior nível de organização e formulação de suas reivindicações.

${ }^{10}$ OLIVEIRA, Lúcia Lippi (1987):O movimento Operário em São Paulo (1970-1985) In: SADER (org.) Movimentos Sociais na Transição Democrática.São Paulo, Cortez.p.235 
No final dos anos 1980, a crise nos países da Europa oriental, impactou partidos e militantes sindicais em suas convicções ideológicas. Algumas lideranças tiveram, assim, dificuldades para continuar formulando estratégias contra o grande capital através das lutas sindicais. Mas os eventos mais devastadores para o proletariado só estavam começando. $\mathrm{E}$ os anos 90 deixam bem claro o impacto das transformações na economia e desregulamentações no mercado de trabalho, que foram responsáveis pelo alto número de demissões. Este fenômeno prejudicou imensamente as finanças dos sindicatos, erodindo a base da organização e imprimindo ao movimento mudanças estratégicas.

O movimento estudantil no Brasil também merece ser mencionado pelo papel de destaque que ocupou nas lutas pela democratização do país. Como mencionamos anteriormente, desde o Golpe Militar de 1964 os estudantes formavam uma resistência contra o regime, expressando-se por meio de jornais clandestinos, músicas e manifestações, apesar da intensa repressão. Podemos dizer que até novembro de 1968 o movimento resistiu intensamente, até que em dezembro do mesmo ano, durante o governo do marechal Arthur da Costa e Silva, foi assinado e decretado o Ato Institucional número 5 (AI5), já mencionado em nota anterior, que cassou a liberdade individual, acabando com a garantia de Habeas Corpus da população. Após um longo período de paralisia forçada, o movimento estudantil parece renascer no ano de 1979, quando as entidades estudantis começam a ser reativadas. Nesse ano acontece a primeira eleição por voto direto na história da UNE. Assim o movimento estudantil emerge para os anos 1980 ampliando suas forças e lutas pela redemocratização do país.

No ano de 1984 a palavra de ordem era : "1,2,3,4,5 mil. Queremos eleger o presidente do Brasil!!!’ Diretas Já! - movimento da população, com participação fundamental dos estudantes e dos políticos progressistas, para a volta das eleições diretas para presidente no Brasil. O congresso votou a favor das eleições indiretas e Tancredo Neves foi nomeado presidente para o próximo mandato (a partir de 1985). Ficou decidido que as próximas eleições, em 1989, seriam diretas. Em 1992, mais uma vez, articulados as grandes lutas nacionais os estudantes voltam às ruas através de sucessivas manifestações contra a corrupção no governo, dando início ao movimento de estudantes chamado Caras Pintadas, que resultou no Impeachment do então Presidente da República, Fernando Collor de Melo. A partir de então a sociedade brasileira não mais assiste as manifestações políticas articuladas as grandes lutas nacionais por parte do seus estudantes. 


\section{Movimento Estudantil no Brasil do Século XXI: da ausência à busca de novos protagonismos}

É importante percebermos que em 1968, o Brasil tinha quase 300 mil alunos no ensino superior, mas o movimento estudantil promovia manifestações do porte da passeata dos Cem Mil, no Rio. Em 2008 o país tem quase 5 milhões de universitários, mas os protestos de rua praticamente desapareceram. Na opinião do historiador Renato Cancian, ${ }^{11} \mathrm{da}$ Universidade Federal de São Carlos, o movimento estudantil sofreu uma inflexão no final dos anos 70, quando passou a ser liderado por militantes das organizações de esquerda que priorizavam as reivindicações políticas em detrimento das demandas educacionais. Essa subordinação à agenda política conduziu aos protestos desse período em defesa das liberdades democráticas, mas provocou um longo refluxo, que persiste até hoje, em razão do distanciamento da maioria dos alunos. Para Cancian, o movimento estudantil sempre teve a sua maior força nas Universidades e o movimento de 1992 dos Cara Pintadas, contou com os estudantes de ensino médio, não sendo uma experiência típica do movimento estudantil brasileiro. Em realidade, o século XXI, até o momento, ainda não foi palco de expressivas manifestações de estudantes, como em décadas passadas do século XX.

Mesmo os movimentos sindicais e o movimento estudantil, cujas experiências são anteriores as lutas pela redemocratização do país, ganham um caráter novo em termos de mobilização nos anos supra citados. A análise do declínio nacional desses movimentos contribui para o registro da memória histórica dos mesmos, para o debate sobre as tendências e as perspectivas de mudança e de transformação da sociedade brasileira que foram construídas nesses períodos. Se novos atores entraram em cena expressando a face de uma nova sociedade civil, a presença dos mesmos no final da década de 90 do século XX e início do século XXI revela uma mudança de cenário que não mais lhes conferem o mesmo protagonismo nacional .

Se consideramos o debate em torno do movimento estudantil, no período político inaugurado logo após o término do regime militar, o que poderemos perceber é uma espécie de onda de desinteresse dos estudantes pelo temas mais significativos da política nacional. A presença marcante dos estudantes na cena política nacional volta a ocorrer apenas nos anos noventa, dentre as inúmeras manifestações políticas que envolveram os movimentos sociais brasileiros nesse período, na luta pelo impeachment do Presidente Collor

\footnotetext{
${ }^{11}$ Opinião transmitida por CANCIAN, Renato através de entrevista realizada por PULS, Maurício (intitulada: Para Historiador, militância enfraqueceu estudantes) ao Jornal Folha de São Paulo, em 17 de março de 2008, disponível no site: www.folha.com.br
} 
de Mello. Ao contrário da experiência anterior, dessa vez no movimento estudantil a maior parte de seus militantes não era das universidade, mas sim do ensino médio da educação, conforme já dissemos.

Não é casual que esse aspecto tenha se revelado nesse momento. O ensino médio brasileiro sofria fortes abalos oriundos da falta de investimentos na esfera pública. Nesse contexto, era grande a busca por vagas nas instituições privadas de ensino que, sem regulamentações, tinham mensalidades reajustadas com freqüência, fora do controle das classes médias que haviam abandonado o ensino da esfera pública devido à má qualidade do mesmo, oriunda da degradação da esfera pública. A efervescência dessa questão parece ter sido ainda mais ampliada após os primeiros apontamentos do Ministério da Educação do governo de Fernando Henrique Cardoso, com relação à nova política universitária do país. Neste sentido, não seria exagero observar que a premissa para o reinício da mobilização dos estudantes, na década de noventa, foi a guinada da universidade para a "mentalidade privatizante" que as reformas estruturais de cunho neoliberal, centradas na desregulamentação dos mercados, na abertura comercial e financeira, na privatização do setor público e na redução do Estado, promoveram.

\section{O Movimento Estudantil no Contexto Neoliberal}

A avalanche neoliberal que o Brasil começou a assistir na última década do século XX demonstra que os problemas sociais aprofundados nessa quadra histórica que atravessamos não representaram apenas uma retórica, mas um processo com profundas raízes em nossa sociedade. Entretanto, seria um equívoco ignorar que o neoliberalismo promoveu, e continua promovendo, estragos ainda mais sérios do que os já conhecidos. As conseqüências de um modelo injusto e desigual, mesmo para padrões capitalistas, são confundidas com as causas pelo neoliberalismo. Assim, a intervenção do Estado no social é vista como pouco "recomendável”, devendo ser substituída pela lógica do mercado.

Isto posto, é importante entender que as transformações sofridas pela educação superior no Brasil e nos demais países latino-americanos, com a efetivação da agenda política neoliberal, não ocorreram por "geração espontânea", nem por demanda de sua clientela, mas sim, abarcadas por diversas orientações encontradas nos principais documentos dos organismos multilaterais, como o Banco Mundial, assim como na cartilha do Consenso de Washington. Dentre as exigências, destacam-se: a necessidade de que o Estado se desvencilhe da manutenção da educação superior, deixando esta a cargo da iniciativa privada, se ocupando apenas da educação básica e média; 
a indicação é as instituições de ensino superior se organizarem e serem geridas como empresas econômicas.

Essas recomendações pretenderam serem válidas para todos os países, sem considerar as especificidades nacionais e de seus sistemas universitários. Entretanto, elas tiveram maior êxito especialmente nos países de periferia, devido a menor capacidade de resistência das respectivas sociedades civis, organizações científico-acadêmicas e instituições universitárias. Cabe lembrar, que as autoridades brasileiras iniciaram, em 1995, o atual processo de reconfiguração da educação superior no país, dando centralidade ao conceito da educação como um serviço competitivo não-exclusivo do Estado, de autonomia financeira das universidades, em lugar da autonomia de gestão financeira; de contratos de gestão; de público não estatal etc., que permearam as linhas tanto da legislação aprovada pelo parlamento quanto pelos decretos presidenciais e das portarias do Ministério da Educação.

O ajuste promovido pelo neoliberalismo tornou o ensino superior um mercado promissor que despertou interesses empresariais (LESSA) ${ }^{12}$. A lógica empresarial deu ao ensino superior do país uma nova cara, muito diferente das universidades e centros de excelência baseados no tripé ensino-pesquisaextensão. Tendo como pressuposto a lógica do mercado, a instalação de um novo estabelecimento de ensino não se norteia mais pelo desenvolvimento nacional, mas pelas possibilidades de ser lucrativo ao seu dono.

O objetivo das iniciativas empresariais é oferecer um produto vendável para mais pessoas e com margens de lucro vantajosas, ainda que com baixa qualidade. O que conta é ter consumidores para o produto à venda: a educação. $^{13}$

Sem entendermos os custos sociais dos ajustes neoliberais e seus impactos na educação pública, não podemos compreender a perda do protagonismo nacional do movimento estudantil no Brasil. Entretanto, a quase ausência nas lutas articuladas aos grandes temas nacionais não significou a morte do movimento estudantil. Ao contrário, a mudança de estratégias e de ação do movimento estudantil, no fundo, representa as possibilidades de resistência dentro de um novo contexto em que o neoliberalismo se impôs como uma avalanche, que destruiu e redirecionou a atuação do Estado brasileiro no enfrentamento da questão social. Conseqüentemente os estragos do

\footnotetext{
${ }^{12}$ LESSA, Carlos. (1999):A universidade e a pós-modernidade: o panorama brasileiro In Dados v.42 No.1 Rio de Janeiro. p. 23-64

${ }^{13}$ DRUCK, Graça; FILGUEIRAS, Luiz (1997): O projeto do Banco Mundial, o governo FHC e a privatização das universidades federais. Plural, São Paulo, FFLCH-Sociologia/ USP, v.6, $n^{\circ} 9,1^{\circ}$ sem., p. 15-27.
} 
neoliberalismo na educação pública, lócus privilegiado da organização e manifestação política, não foram pequenos e abalaram a organização dos estudantes brasileiros. Por esse motivo, apesar de todas as adversidades, é importante registrar que recentemente o movimento estudantil no Brasil apresentou um certo revigoramento, sobretudo, a partir do ano de 2007, quando os estudantes voltaram a se mobilizar em âmbito local. A ocupação da reitoria da Universidade de São Paulo contra os decretos do governador de São Paulo, José Serra, pode ser considerada o ponto de partida de um novo movimento estudantil, que voltou a se organizar para questionar os rumos da educação. A partir daí podemos observar, ainda no âmbito local, a existência de atos, greves, manifestações e dezenas de ocupações de reitorias. Assim foi nas universidades federais, onde os estudantes protagonizaram inúmeras ocupações contra o decreto do presidente da República Luís Inácio da Silva Lula, sobre a Reforma Universitária - Reuni.

Os estudantes começaram o ano de 2008 mostrando que estavam errados aqueles que diziam que essas novas expressões de suas lutas eram passageiras. O movimento estudantil demonstrou que tem fôlego para seguir lutando e arrancando conquistas, mesmo que localizadas. Foi o que ocorreu na Universidade de Brasília (UnB). O escândalo de corrupção envolvendo a Fundação Privada da Universidade (Finatec) e o reitor, Timothy Mulholand ${ }^{14}$, foi a faísca que incendiou os estudantes da UnB.

Os estudantes não ficaram parados diante dos escândalos. No dia 3 de abril de 2008, realizaram um grande ato e ocuparam a reitoria exigindo a renúncia do reitor. A partir daí, foram realizadas novas assembléias, debates e manifestações. A ocupação se tornou notícia Brasil afora. Estudantes de todo o país se posicionaram a favor da ocupação na UnB. Nove dias depois, o vice-reitor, Mamiya renunciava. No dia seguinte, o reitor Timothy e todo o decanato da Universidade também renunciaram.

A renúncia de do Reitor Timothy, do vice-reitor Mamiya e outros membros da administração, foi uma grande vitória e demonstrou a força do movimento. A partir da queda do máximo dirigente da universidade, toda a estrutura universitária começou a ser questionada. A luta dos estudantes da UnB levantou bandeiras capazes de denunciar os efeitos perversos do modelo privatista da Universidade Pública.

\footnotetext{
${ }^{14} \mathrm{O}$ reitor $\mathrm{da} \mathrm{UnB}$ usou verbas que eram destinadas à pesquisa na reforma de seu apartamento funcional. Timothy comprou com as verbas da universidade até uma lixeira que custava mil reais.
} 


\section{CONCLUSÃO}

Conforme observou Marilena Chauí, "o neoliberalismo não é uma lei natural nem uma fatalidade histórica nem muito menos o fim da história" (CHAUÍ,1999:512). Entretanto, observa a filósofa, ele é ideologia de uma forma histórica particular assumida pela acumulação do capital, portanto, "algo que os homens fazem em condições determinadas, ainda que não o saibam e que podem deixar de fazer se, tomando consciência delas, decidirem organizar-se contra elas" (idem). Por isso, não podemos ignorar a tragédia da educação brasileira sob os efeitos do projeto neoliberal que, no caso da universidade, implantou-se sem disfarces pelo prisma das relações de mercado. Dando como óbvio que essa lógica é a solução para os problemas educacionais.

Pormais distintas que sejam as experiências e realidades de nossas universidades, as questões que guiaram e continuam a guiar a organização do movimento estudantil em nosso país foram (e continuam sendo) historicamente impulsionadas por um aspecto comum: a percepção de que a universidade não pode caminhar distanciada da realidade social do país. Em outras palavras, se cairmos nas armadilhas contemporâneas que assolam, sobretudo a mídia de nosso país, de que não existe mais movimentos sociais, incluindo os de estudantes, capazes de assumirem um papel transformador, estaremos condenando parcelas ainda majoritárias de jovens brasileiros que ainda não possuem e os que têm acesso ao ensino superior, mas que tampouco têm garantidos seus direitos mais essenciais, a se calarem diante da desvinculação da educação do processo de emancipação humana .

Os anos de rebeldia que marcaram a década de 60 do século XX não voltam mais, o protagonismo internacional e nacional que evidenciou o movimento estudantil em 68 também não volta, mas as lutas por uma educação pública e de qualidade não se apagam tão facilmente. Se essa confirmação ainda continua presente, em condições ultra desfavoráveis, sem dúvida, é sobretudo, devido ao movimento estudantil.

\section{FUENTES Y BIBLIOHEMOGRAFÍA}

Jornal do Brasil de 25 de maio de 1967, p. 34

Jornal do Brasil de 29 de março de 1968, p. 22

Jornal O GLOBO, 22/03/1998, p. 15

\section{SELECCIÓN BIBLIOGRAFICA}

ALBUQUERQUE, J.A. Guilhon. (1977): Movimento Estudantile Consciência Social na América Latina, Rio de Janeiro, Paz e Terra.

ALMEIDA JR., Antônio Mendes de. (1981): Movimento Estudantil no Brasil.São Paulo, Brasiliense, (coleção Tudo É História, No. 23). 
ALVES, María Helena Moreira. (1984): Estado e Oposição no Brasil (1964-1984), Petrópolis, VOZES.

ARANTES, Aldo. (1979): A UNE no Período de 61/62 In: Cadernos de Opinião, No.12, julho.

CANCIAN, Renato. (2008): Para Historiador, militância enfraqueceu estudantes. Entrevista realizada por Maurício Puls. In: Jornal Folha de São Paulo, em 17 de março de 2008, disponível no site: www.folha.com.br

CHAUÍ, Marilena. (1999): Ideologia neoliberal e universidade. In: OLIVEIRA, Francisco e PAOLI, Maria Célia. Os Sentidos da Democracia. Políticas do dissenso e hegemonia global. Petrópolis, Vozes.

DRUCK, Graça; FILGUEIRAS, Luiz. (1997): O projeto do Banco Mundial, o governo FHC e a privatização das universidades federais. Plural, São Paulo, FFLCH-Sociologia/USP, v.6, N. 9, $1^{\circ}$ sem.

FAVERO, Maria de Lourdes de Albuquerque. (1995): UNE em Tempo de Autoritarismo.Rio de Janeiro, Ed. UFRJ.

FERNANDES, Florestan. (1997): A Força do Argumento. Org. João Roberto M. Filho, Editora da UFSCar, São Carlos.

HOBSBAWM, Eric. (1995): A Era dos extremos. O breve século XX: 1914-1991, São Paulo, Companhia das Letras.

LESSA, Carlos. (1999): A universidade e a pós-modernidade: o panorama brasileiro In Dados v.42 n.1 Rio de Janeiro.

MENDES JR., Antônio. (1982):Movimento Estudantil no Brasil, São Paulo, Brasiliense.

OLIVEIRA, Lúcia Lippi. (1987): O movimento Operário em São Paulo (1970-1985) In: SADER (org.) Movimentos Sociais na Transição Democrática.São Paulo, Cortez.

TEIXEIRA, Faustino Luiz C. (1988): A gênese das CEBs No Brasil. 1. ed. São Paulo: Paulinas. V.1. 1993.

(1993): CEBs: cidadania e modernidade. 1. ed. São Paulo: Paulinas,

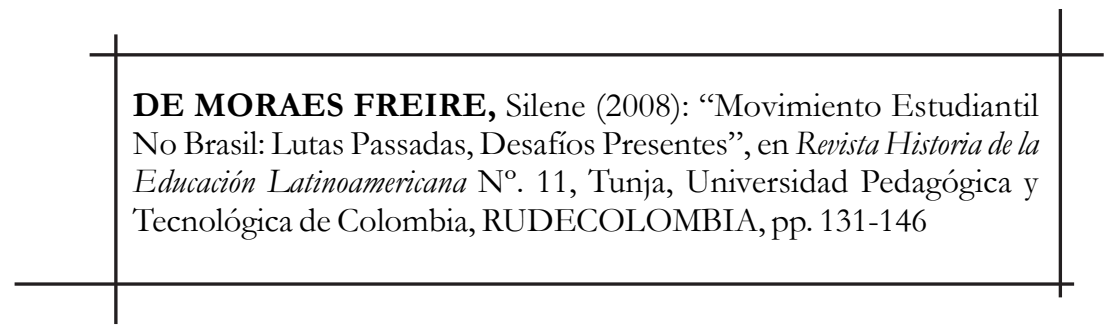

